\title{
Célula Espermática: Projeto e desenvolvimento de objetos educacionais
}

\author{
Eneder Rosana Oberst * \\ Liane Margarida Rockenbach Tarouco** \\ Mary Lucia Pedroso Konrath *** \\ Silvana Vidor ${ }^{* * * *}$ \\ Centro Interdisciplinar de Novas Tecnologias na Educação \\ Universidade Federal do Rio Grande do Sul \\ Brasil
}

\begin{abstract}
Resumo
O presente artigo tem como objetivo discutir a importância da produção de objetos educacionais para o curso de Veterinária com vistas a ensejar uma aprendizagem mais significativa. Através do uso desses recursos a teoria e a prática podem ser enriquecidas, facilitando o processo de ensino e aprendizagem nessa área e diminuindo a sobrecarga cognitiva. Adicionalmente o trabalho apresenta resultados preliminares conseguidos com o uso de objetos educacionais que vem sendo desenvolvidos pelo grupo da Veterinária juntamente com a equipe do Centro Interdisciplinar de Novas Tecnologias na Educação, para ensino-aprendizagem com foco no tema Célula Espermática.
\end{abstract}

Palavras-chave: objetos educacionais, reprodução animal, célula espermática.

\section{Introdução}

Para muitos alunos, alguns conteúdos do ensino de Medicina Veterinária, especialmente aqueles relacionados com estruturas celulares e mecanismos de cascata, tornam-se especialmente difíceis quando são apresentados em descrição em textos ou diagramas, com as nomenclaturas e descrições conectadas através de setas. Através de métodos tradicionais de ensino, conceitos como a noção de que moléculas se movem dentro das células, interagem umas com as outras, mudam sua forma e atividade são mais difíceis de serem atingidos, e requerem maior tempo de estudo.

Com a apresentação desse conteúdo de forma mais apropriada e dinâmica, através de métodos interacionistas de ensino permitem que ele possa ser entendido ao invés de memorizado (Buchanan et al., 2005). Dessa forma, o uso de animações, especialmente aquelas em 3D em outros estudos foi considerado muito eficaz para estas situações, porque reduziu o overload cognitivo, que ocorre quando o aluno tem que aprender um material novo e ao mesmo tempo converter a informação dada imaginando a situação num aspecto tridimensional. Se a informação for apresentada de um modo apropriado, o estudante pode se concentrar sobre o material a ser estudado e seu aprendizado é mais efetivo (Lipson,1992).

Animações e simulações são importantes para demonstrar conceitos que de outra forma não poderiam ser visualizados, como as respostas fisiológicas e interações moleculares.

\footnotetext{
"Doutora em Medicina Veterinária e Professora do Dep. de Patologia e Clínica Veterinária da UFRGS.

**. Doutora em Engenharia Elétrica pela USP, Mestre em Ciência da Computação pela UFRGS.

"*** Mestranda em Educação e Especialista em Informática na Educação pela UFRGS.

Jornalista e aluna do curso de Veterinária da UFRGS.

V. $4 \mathrm{~N}^{\circ} 1$, Julho, 2006
} 
Neste sentido, o uso de CD-ROM e acesso a sites como material de apoio ou substituindo o material impresso têm sido utilizado em várias disciplinas. Além dos aspectos positivos relacionados ao aprendizado, permite aos alunos acessar materiais e vídeos em suas residências, nos horários mais convenientes (Nieder e Nagy, 2002, Brueckner e Traurig, 2003; Blake e Lavoie, 2003; Gómez-Arbonez et al. 2004; Buchanan et. al, 2005).

Com relação ao desempenho dos alunos em programas de treinamento médico em Cirurgia e Histologia, o escore dos indivíduos que utilizaram material didático virtual em CD-ROM, foi superior aos que utilizaram métodos tradicionais de aprendizado (Gold et al. 2004; Gold et al,. 2002; Thomas e Allen, 2003; Blake et al., 2003).

Da mesma forma, no Curso de Medicina Veterinária, o uso de CD como material de apoio para a disciplina de Cirurgia, em lugar de textos impressos, foi aprovado por $90 \%$ dos usuários, que na grande maioria, consideraram que obtiveram aprendizado superior ao alcançado com os métodos tradicionais (Howe et al., 2005).

Uma importante iniciativa no ensino de Veterinária utilizando meios multimídia, é o Projeto CLIVE (Computer-Aided Learning in Veterinary Education), iniciado em 1992, cujo objetivo original era utilizar o ensino com o uso de computadores nas disciplinas dos cursos de Veterinária no Reino Unido. Atualmente, 14 Universidades de diferentes países estão associadas ao projeto, que recebe fundos da União Européia. Alguns blocos de conteúdo foram desenhados para substituir aulas práticas, por razões de custo e éticas, como por exemplo, Gliconeogênese, Simulação prática da musculatura cardíaca, enquanto que outros (Patologia Geral -Tutorial e Testes) foram desenvolvidos como material para auxiliar para estudo. Em avaliação recente, $90 \%$ dos usuários consideraram que o material auxiliou no aprendizado, é fácil de usar e foi excelente na informação visual (Dale et al. 2005).

Na Veterinária, a área de Reprodução Animal e suas Biotecnologias têm experimentado grandes avanços científicos e tecnológicos de modo constante e é comum que o aluno de graduação tenha acesso a bibliografias atuais, especialmente pela utilização do Portal Capes, que dá acesso a inúmeros periódicos científicos. Mas em decorrência de ser este tipo de material bastante especializado e específico, verifica-se que o aluno encontra dificuldade em aproveitá-lo, muitas vezes por falta de um conteúdo básico anterior. Além disso, os materiais bibliográficos, de um modo geral, ou são muito superficiais, ou muito fragmentados e específicos. Em qualquer caso, estas dificuldades desestimulam o aluno, ou no mínimo, dificultam e retardam seu processo de busca.

No curso de Veterinária da UFRGS a disciplina de graduação, VET 03 323, Inseminação Artificial destina $60 \%$ do conteúdo teórico/prático para o estudo e análises da célula espermática e possui grande número de aulas práticas, que possibilitam que o aluno manipule e analise amostras de sêmen de várias espécies (bovinos, ovinos, caprinos, suínos e eqüinos). Ainda assim, inúmeros aspectos teóricos, entre os quais a motilidade espermática, são difíceis de serem entendidos através de gravuras ou esquemas, ou mesmo pela observação das amostras ao microscópio.

\section{O desenvolvimento de objetos de aprendizagem}

Buscando novas estratégias para apoio ao processo de ensino-aprendizagem nesta disciplina, o grupo submeteu proposta de construção de objetos de aprendizagem em resposta ao Edital 2005 da Secretaria de Educação a Distância da UFRGS. Assim está sendo realizado um projeto para a produção de objetos educacionais para esta área: 
Célula Espermática, Motilidade Espermática e Trânsito Epididimário, que serão utilizados nas disciplinas de Inseminação Artificial, Fisiologia Veterinária e Tecnologia do Sêmen, como material complementar.

O planejamento e construção dos objetos buscam consonância com as recomendações concernentes ao uso de multimídia bem como cuidados no uso de redundância controlada de informações (Mayer, 2001).

A seguir, serão descritos aspectos considerados e decisões de projeto relativas ao primeiro destes objetos, a célula espermática.

\subsection{O objeto de aprendizagem Célula Espermática}

O primeiro objeto a ser desenvolvido foi o referente a Célula espermática. A sua escolha foi baseada em dois fatores: oferecer informações básicas, importantes para os próximos dois objetos e tratar de um tipo de conteúdo que não requer um nível muito aprofundado de interação e de simulação, sendo possível desenvolvê-lo ao mesmo tempo em que as pessoas envolvidas no projeto adquirissem experiência no uso das ferramentas de autoria e nos conceitos de educação à distância.

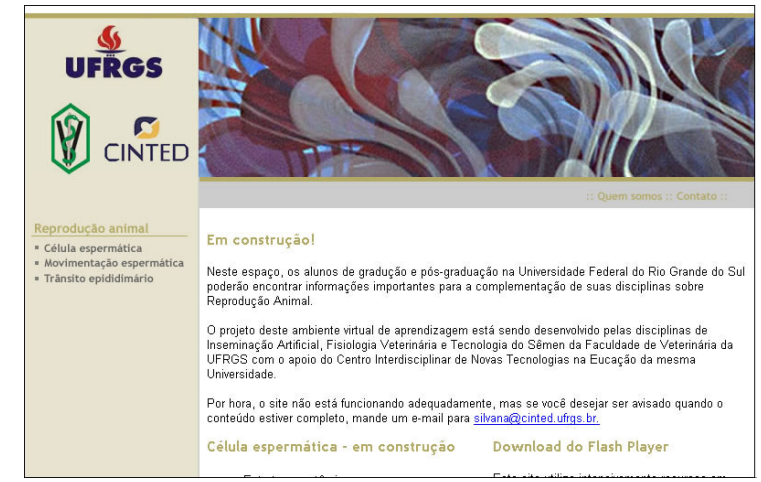

Figura 1 - Página inicial do objeto educacional Célula espermática

O primeiro passo na criação deste objeto foi projetar uma interface de navegação que deveria:

- ser simples e clara para diminuir a necessidade de aprendizado dos alunos sobre a navegação e permitir que focassem no conteúdo

- (2) ser visualmente atrativa com a combinação harmônica de fontes de texto, cores e imagens

- (3) apresentar uma estrutura de navegação genérica que funcionasse bem com diferentes conteúdos a serem apresentados

- (4) utilizar uma tecnologia que permitisse o acesso remoto ou local dos conteúdos e que permitisse realizar atualizações rapidamente.

A montagem do ambiente foi toda baseada em HTML, com vistas a facilitar o processo de atualização e aperfeiçoamento da parte de texto e interligação dos diferentres segmentos do material. As animações em Macromedia Flash e vídeos no formato MPEG foram incluídos/embutidas nas páginas HTML construídas.

A figura 2 mostra exemplos da interface construída: 


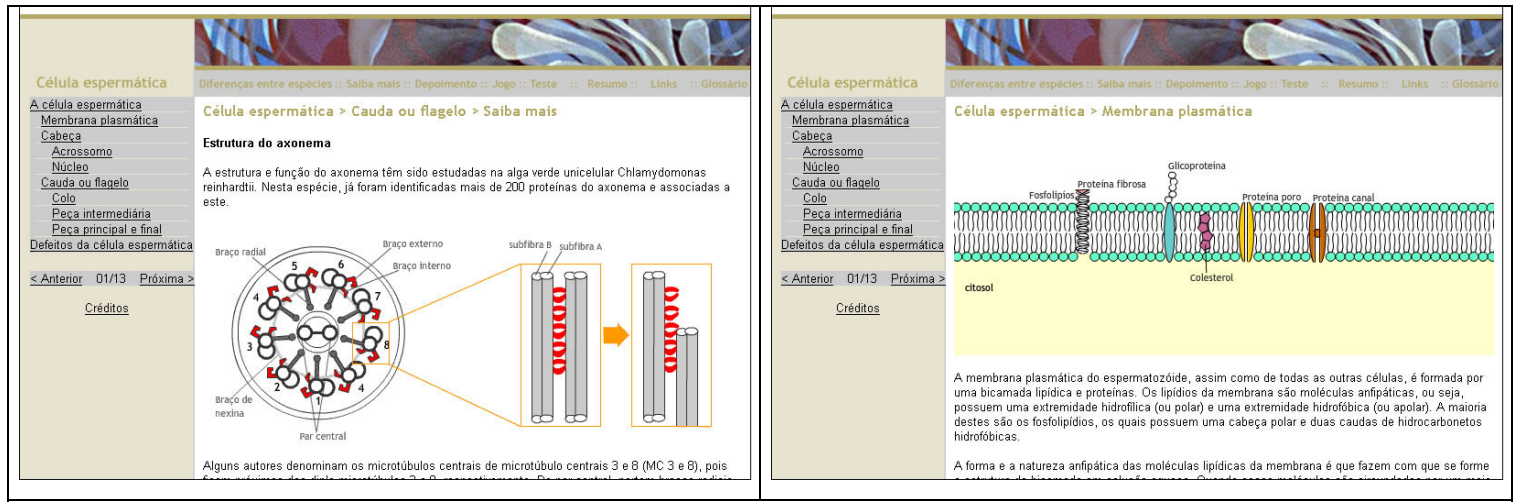

Figura 2 - Interface de navegação de Célula espermática

$\mathrm{Na}$ interface de navegação foram utilizados tons de bege e cinza, procurando manter as cores neutras em relação à apresentação do conteúdo e integrando-as à imagem temática utilizada. Esta última foi fornecida pelo artista plástico Max Springer, que compõe uma de suas coleções de imagens, inspirada em imagens de microscopia de células espermáticas.

Todos os desenhos apresentam contornos pretos, objetivando a clareza das formas, essencial para o entendimento das peças anatômicas apresentadas. Os desenhos foram coloridos com paletas de cores diferentes para cada assunto, buscando fugir da monotonia tal como ilustrado na Figura 2.

Outros aspectos do projeto visual deste objeto de aprendizagem foram os seguintes:

- A navegação pelos conteúdos foi planejada para contemplar diferentes estilos de navegação. Alunos mais habituados às linguagens da Internet têm à disposição a navegação através dos links, enquanto os mais lineares podem navegar através dos botões -anterior e próximo como se estivessem utilizando um livro. A referência de numeração de página (05/18?) oferece ainda ao aluno a informação da quantidade de conteúdo percorrido e do conteúdo a percorrer, importante para que ele tenha uma noção do total do material e não se sinta perdido.

- O conceito criado para a arquitetura de informação foi apresentar a lista de conteúdos num menu vertical à esquerda. Esse menu apresenta um formato semelhante a um sumário, em que a hierarquia do conteúdo foi preservada através da indentação:

1) A célula espermática;

(1.1) Membrana plasmática;

(1.2) Cabeça;

(1.2.1) Acrossomo;

(1.2.2) Núcleo;

(1.3) Cauda ou flagelo;

(1.3.1) Colo;

(1.3.2) Peça intermediária;

(1.3.3) Peça principal e final;

(1.4) Defeitos da célula espermática. 
Cada item do menu de conteúdo apresenta uma página principal e cinco subitens relacionados a ele: diferenças entre espécies, saiba mais, depoimento, jogo, teste. Apresenta ainda três itens genéricos que fazem parte do objeto: resumo, links e glossário.

- Na página principal da cada conteúdo é apresentado um modelo genérico, independente de espécie, com informações referentes à sua estrutura e sua função na célula espermática:

a) Como o conteúdo é relativo a diferentes espécies, o subitem Diferenças entre Espécies procurou mostrar detalhes particulares de cada espécie ou fazer a comparação entre a mesma estrutura em diferentes espécies.

b) O subitem Saiba Mais disponibiliza detalhes, informações curiosas ou mais aprofundadas de conteúdo opcionais, contemplando alunos que já apresentam o domínio do conteúdo principal.

c) Os Depoimentos buscam mostrar ao aluno a relevância do assunto tratado a partir de vídeos em que especialistas expõem seus conhecimentos.

d) Os Jogos têm o objetivo de trabalhar a retenção do conteúdo, ensejar um processo de auto-avaliação pelo aluno e oportunizar um maior grau de interação constituindo ferramentas de aprendizagem eficientes, pois eles divertem enquanto motivam, facilitam o aprendizado e aumentam a capacidade de retenção do que foi ensinado, exercitando as funções mentais e intelectuais do jogador (Tarouco 2004).

e) No subitem Teste, foi colocada uma pergunta relacionada com o conteúdo tratado, mas que deve ser respondida a partir de pesquisa adicional. Trata-se de um pequeno desafio oferecido ao aluno com a indicação de um local onde as respostas podem ser encontradas.

f) A página de links apresenta uma lista de endereços de Internet e de revistas científicas que abordam temas relacionados.

g) O glossário apresenta uma lista de vocabulário complementar importante para a aquisição do conhecimento proposto.

h) Cada página apresenta uma área superior reservada para animações e/ou esquemas e, abaixo desta, segue o texto que complementa a informação. Dandose assim uma ênfase à informação visual. Nesse objeto, era preciso apresentar as diferentes peças anatômicas que compõem a célula espermática e as funções de cada estrutura.

\subsection{Dificuldades observadas}

O projeto e construção de objetos de aprendizagem utiliza intensamente imagens, além do material textual. O processo de obtenção deste material não é trivial enfrenta uma série de dificuldades. As estratégias utilizadas para contornar algumas delas foram as seguintes:

- Seleção de material bibliográfico: embora já selecionados previamente, houve grande dificuldade na escolha dos materiais, pois há uma grande variação de nomenclaturas, incorreções e problemas de tradução, mesmo em obras consagradas. Houve demora na resposta das solicitações de liberação de fotos e imagens e muitas vezes nem houve resposta.

- Nível e abrangência de conteúdos: a opção foi apresentar os conteúdos em nível elementar, mais próximo ao que é trabalhado ao nível da Graduação. Entretanto, 
como são inter relacionados com diversos eventos fisiológicos, em várias espécies, foi difícil restringir os conteúdos. Para minimizar tal dificuldade foi criado o Saiba Mais

- Diversas espécies: O conteúdo foi apresentado tomando como padrão a espécie bovina, e como opção de navegação: Diferenças Entre as Espécies.

- Pouca experiência do professor especialista no conteúdo em relação ao uso da tecnologia. Esta dificuldade foi minimizada pelo apoio fornecido pelo CINTED, pela experiência do desenvolvedor e pela qualificação do professor através dos cursos organizados pela SEAD-UFRGS.

\section{Considerações Finais}

Embora o objeto Célula Espermática não tenha sido ainda testado com turmas de alunos de graduação, uma análise do mesmo foi feita com um grupo de alunos que atuam como bolsistas de graduação do Laboratório de Inseminação Artificial. Nesta avaliação preliminar foi possível constatar que:

- O material produzido até o momento está apresentado de forma concisa, porém não superficial,

- É ilustrativo e claro, especialmente nas estruturas do flagelo espermático (que sempre suscitam dúvidas nos alunos),

- A apresentação dos conteúdos tem um encadeamento didático que facilita o seu entendimento,

- Os jogos tornam o material lúdico e aumentam a motivação mas não podem ser projetados e construídos sem um profundo conhecimento da área temática esse conhecimento deve ainda estar atrelado a princípios teórico-metodológicos claros e bem fundamentados.

Para os próximos objetos a serem desenvolvidos até o final de 2006, pretende-se continuar a utilizar esta mesma interface. Dessa forma, o aluno poderá utilizar a experiência de navegação com a qual está familiarizado o que reduzirá a carga cognitiva estranha ao conteúdo, conforme proposto por Sweller (2005).

A produção desses objetos de aprendizagem busca ensejar condições para uma aprendizagem significativa que os capacite a processos cognitivos superiores em lugar de simples aprendizagem mecânica, conforme salientado por Ausubel (1978). Pelos inúmeros projetos aprovados pelo edital da SEAD-UFRGS é possível perceber que os professores têm voltado sua atenção para a a produção e uso de materiais de apoio para o ensino presencial e/ou a distância que dêem conta de aprimorar a prática de sala de aula, como forma de enriquecer e facilitar o processo de ensino-aprendizagem nas mais diversificadas áreas. $\mathrm{O}$ processo educacional está sendo afetado por essas novas Tecnologias de Informação e Comunicação (TICs) e dessa forma, professores que têm computadores a sua disposição começaram a utilizá-los no contexto educacional de forma que seu aluno possa construir seu conhecimento - enfatizando a participação e experimentação desse sujeito na construção de seu próprio conhecimento, por meio de suas interações.

A disponibilização desses materiais via Internet permite o seu acesso por um número bem maior de usuários, incluindo alunos e professores de outras Universidades dentro e fora do Brasil, assim como permite a qualificação do ensino, na qual as tecnologias são apenas ferramentas que permitem o compartilhamento de conhecimentos que até então estavam restritos aos grandes centros acadêmicos. Com isso, estas permitem que o 
resultado da atividade de produção de material educacional digital pelo professores alcancem maior número de pessoas, proporcionem diferentes tipos de aprendizado e possibilitem ainda que o aprendizado seja divertido e exercido com criatividade, pelo uso de diferentes meios (Bernardo, 2003)

\section{Referências}

AUSUBEL, David Paul. Novak, Joseph Donald. Hanesian, Helen. Psicologia educacional. 2.ed. Rio de Janeiro: Interamericana, 1978. $625 \mathrm{p}$.

BERNARDO, T. M. Informatic and Technology Approaches to Veterinary Education New Technology Imperatives in Medical Education. Journal of Veterinary Medical Education. n.30, v.4, p. 318-325, 2003.

BLAKE, C. A.; LAVOIE H. A.; MILLETTE, C. F. Teaching medical histology at the University of South Carolina School of Medicine: Transition to virtual slides and virtual microscopes. Anat Rec. n.275, p 196-206, 2003.

BRUECKNER, J. K.; TRAURIG, H. Students responses to the introduction of a digital laboratory guide in medical neuroscience. Med Teach. n.25, p. 643?648, 2003.

BUCHANAN, M.F.; CARTER, W.C.; COWGILL, L.M.; HURLEY, D. J., LEWIS, J.S.; MACLEOD, J.; MELTON, T.R. ;MOORE, J.N. ;PESSAH, I.; ROBERTSON,T. P.; SMITH, M. L.; VANDENPLAS, M.L. Using 3D Animations to Teach Intracellular Signal Transduction Mechanisms: Taking the Arrows out of Cells. Journal of Veterinary Medical Education n.32, p. 72-78, 2005.

DALE, V.H.M.; Mc CONNELL, G.; SHORT, A.; SULLIVAN, M. Ten Years of CLIVE (Computer-Aided Learning in Veterinary Education) in the United Kingdom. Journal of Veterinary Medical Education, n. 32, p. 47-50, 2005.

GOLD J.P; BEGG, W.B.; FULLERTON, D.; MATHISEN, D.; OLINGER, G.; ORRINGER, M.; VERRIER, E. Successful implementation of a novel internet hybrid surgery curriculum: The early phase outcome of thoracic surgery prerequisite curriculum e-learning project. Ann. Surg.n. 240, p. :499-507, 2004.

GOLD, J.P.; VERRIER, E. A.; OLINGER, G. N.; ORRINGER, M.B. Development of a CD-ROM Internet hybrid: A new thoracic surgery curriculum. Ann. Thor. Surg.n. 74, p.1741-1746, 2002.

GOMEZ-ARBONES, X.; FERREIRA, A.; PIQUE, M.; ROCA, J.;TOMAS, J.; FRUTOS, J. L.; VINYAS, J.; PRAT J. A cardiological web as an adjunct to medical teaching: Prospective analysis. Med Teach. n.26, p 187-189, 2004.

HOWE, L. M.; BOOTHE, H. W. J.; HARTSFIELD, S. M. Student Assessment of the Educational Benefits of Using a CD-ROM for Instruction of Basic Surgical Skills. Journal of Veterinary Medical Education. n.21, p 138-143, 2005.

MAYER, R. E. ; HEISER, J. ; LONN, S. ; Cognitive constraints and multimedia learning: when presenting more material results in less understanding ; Journal of education psychology 2001, vol. 93, n. 1, 187-198. 
NIEDER, G. L.; NAGY, F. Analysis of medical students: use of Web-based resources for a gross anatomy and embryology course. Clin Anat. n.15, p 409-418, 2002.

SWELLER, John. Merrienboer, J. Cognitive Load Theory and Complex Learning: Recent Developments and Future Directions. Educational Psychology Review, Vol. 17, No. 2, June 2005

TAROUCO, Liane. Jogos Educacionais. Revista Novas Tecnologias na Educação. V. 2 $\mathrm{N}^{\circ}$ 1, Março, 2004. CINTED/UFRGS. Porto Alegre-RS. Acesso em Junho/2006 http://www.cinted.ufrgs.br/renote/

THOMAS, R. L.; ALLEN, R. M. Use of computer-assisted learning module to achieve ACGME competencies in orthopaedic foot and ankle surgery. Foot \& Ankle Intern. n.24, p. 938-941, 2003. 